\title{
UK-Cuboid Randomized Complete Block Design: A Complete Three Way Layout for Large Multi- Center Clinical Trials
}

\author{
N. Uthayakumaran \\ NIE, ICMR, Chennai, Tamilnadu, India
}

\begin{abstract}
In clinical epidemiology research, if principal investigator needs to know whether specific drug which has been invented is advantageous or not in the treatment of particular disease, there are many experimental designs to approach, in which most significant one is Latin Square Design (LSD). The LSD has its own merits and demerits. The major disadvantages of LSD are 1) Incomplete threeway layout. 2) Difficult to handle large sample size and 3) The analysis of data in LSD is conditional. It is an attempt to provide a new design of experiment to overcome all these disadvantages with additional benefits and also useful for large multi-center clinical trials. $A$ new design of an experiment is an effort to extend UK-Cubic complete random design (UKCD) towards UK-Cuboid randomized complete block design (UKCBD) to provide a way to include larger number of treatments and unequal/equal number of levels (characteristics that differentiate factors) of the various independent variables effortlessly. The depending study variable is simulated using the simulated model. Each term in the simulated model, plus the simulated model as a whole, is tested using ANOVA for its ability to account for variation in the dependent variable, to reveal the efficiency of the UKCBD design. Simulation model is used to have values of depending study variable "hemoglobin level of anemic patients" for the operation of the assumed Phase III multi-center clinical trial for the 192 anemic patients arranged in the original order of the three factors such as, 2 age-groups, 3 centers and 4 districts in such a way that four treatments randomly allocated to twenty four cells which have 2 blocks based on gender (Female, Male) and 4 anemic patients in each block. The analysis tools ANOVA and post hoc tests imply with the independent variables such as treatment, age-groups, centers, districts and blocks that the outcome of treatments of anemic patients is correctly found as per simulation for the randomized data of depending study variable. The mean hemoglobin level of anemic patients under the new drugs is significantly better than that under placebo as in simulated order. It reveals the efficiency of this design and its good randomization. In real life situation, it is not always possible to form equal number of levels with all the associate factors. Using this new design, it is possible to accommodate either unequal or equal number of levels of the associated factors. This design will be useful for large multicenter clinical trials. It includes larger number of participants, more number of treatments, different geographic locations, wider range of population groups and the ability to compare results among centers, all of which increase the generalizablity of the multi-center clinical trial study. It also controls more variation and results in a smaller mean square error.
\end{abstract}

Keywords: Large multi-center clinical trial study- Complete three way layout- Larger number of participants-Larger number of treatments-Unequal/equal number of levels

\section{Introduction}

In general, the experimental designs have been demonstrated by many authors for their usefulness in collection, analysis and inference, for example see [1], [2] and [3]. An experimental design is a way to carefully plan the experiments in advance so that results are both objective and valid. Ideally, the experimental design should describe how the participants are allocated to the experimental groups. The common method is Completely Randomized Design (CRD), where the participants are assigned to groups at random [4]. In most of the experiments, the available experimental units are grouped into blocks having more or less identical characteristics to remove the blocking effect from the experimental error. Such a design is termed as block design. The number of experimental units in block is called block size. If block size is equal to the number of treatments and each treatment in each block is randomly allocated, then it is full replication and the design is called as complete block design. One such method is Randomized Block Design (RBD), where the participants are divided into homogeneous blocks before being randomly assigned to groups [5].

Minimize or eliminate more number of confounding variables, which can offer the alternative explanations for the experimental results. It allows making inference about the relationship between dependent and independent variables [4]. Motivated by this, Latin Square Design (LSD) has been demonstrated in several studies. LSD has its own advantages and disadvantages. LSD is assumed to be a three factor experiment but actually it has only two- way stratification. Analysis is done with the missing blocks since it is an incomplete three way layout. In LSD, the experimental material is divided into rows and columns, each having the same number of experimental units which is equal to the number of treatments. To overcome this limitation, UKCD [6] design of experiment has been introduced by extending LSD. It produces a complete three way layout so that analysis is done without missing blocks In this design, number of experimental units in blocks is equal but need not equal to the number of treatments, in turn; it is possible to handle large sample size. It also controls more variation and results in a smaller mean square error. In this design, it is possible to include larger number of participants, different geographic locations, wider range of population groups and the ability to compare results among centers, all of which increase the generalizablity of the multi-center clinical trial study. The limitation of this design is that it compares treatments by considering the associated factors with equal levels and those levels equal to the number of treatments. In real life situations, it is not often to get the associated factors with an equal number of

Volume 6 Issue 12, December 2017 


\section{International Journal of Science and Research (IJSR) \\ ISSN (Online): 2319-7064}

Index Copernicus Value (2016): 79.57 | Impact Factor (2015): 6.391

levels. To go along with the real life situations, UK-Cuboid complete randomized block design (UKCBD) has been developed to arrange the associated factors with different levels. It may also be noted that UKCBD is an attempt to extend UKCD towards block design to provide a way to include larger number of treatments effortlessly and reduce additional variability to make it easier to find the differences in treatment outcomes.

\section{Methods}

\subsection{UKCBD- Design of experiment}

UKCBD of order $\mathbf{n}_{1} \times \mathbf{n}_{\mathbf{2}} \times \mathbf{n}_{\mathbf{3}}$ is a design [7],[8],[9],[10] to allocate $\mathbf{r}$ treatments to the sampling units which is in multiples of $\mathbf{r}$ in each cells and equal size in all the $\mathbf{n}_{1} \mathbf{x} \mathbf{n}_{\mathbf{2}} \mathbf{x}$ $\mathbf{n}_{\mathbf{3}}$ cells arranged in $\mathbf{n}_{\mathbf{1}}$ rows, $\mathbf{n}_{\mathbf{2}}$ columns and $\mathbf{n}_{\mathbf{3}}$ altitudes in natural order. For example, initially to frame UKCBD of order $2 \times 3 \times 4$, there are 24 cells and let 8 sampling units in each cell. Each cell is divided into 2 blocks which has 4 sampling units each equal to number of treatments. As a first step, randomly allocate four treatments to the 4 sampling units in each block of all the cells, using random number table.

That is, in step-1, select first set of four random numbers randomly. Use the ranks of these random numbers to allocate the four treatments for four sampling units in a first block. Select second set of four random numbers randomly again use rank of these four random numbers to allocate four sampling units in a second block. The similar process of randomization may be repeated in first and second blocks of all the cells to allocate the different combination of treatments in each block to form the base design layout.

In step-2, select again a set of two random numbers randomly. Use the ranks of these random numbers to select the existing row numbers of each altitude-level and arrange them in the design layout accordingly.

In step-3, column numbers of each altitude-level should be randomized in a similar way, using the same procedure for the rearrangement. Again a new set of randomly selected three random numbers is used with their ranks to select the column numbers of each altitude-level and rearrange them in the design layout respectively.

In step-4, altitude numbers should be randomized in a similar way using the same procedure for further rearrangement. Use the fresh set of randomly selected four random numbers with their ranks to select the altitude numbers to further rearrange them in this ranking order which is the final design layout plan of the experiment.

Once the experiment is designed properly, the depending study variable is simulated using the following simulated linear model. Each term in the simulated model, plus the simulated model as a whole, is tested for its ability to account for variation in the dependent variable.

$\mathrm{Y}_{\mathrm{ijkbs}}=(\mathrm{i}+\mathrm{j}+\mathrm{k}+\mathrm{b}) * \mathrm{t}+\mathrm{s}$,

$\mathrm{i}=1,2, \ldots, \mathrm{n}_{1}$

$\mathrm{j}=1,2, \ldots, \mathrm{n}_{2}$ $\mathrm{k}=1,2, \ldots, \mathrm{n}_{3}$

(Serial numbers of rows, columns, altitudes and treatments in the initial plan),

$\mathrm{b}=1,2, \ldots, \mathrm{m}$

(Serial numbers of the blocks)

\&

( $\mathrm{t}=$ Relevant scores for treatments in the blocks)

( $\mathrm{s}=$ Relevant scores for sampling units in the blocks)

to reveal the efficiency of the UKCBD design using the illustration described below:

\subsection{Illustration}

For clinical study management training and analysis, clinical study simulation plays an important role. It is useful in real life clinical studies to produce reliable analysis and to support decision-making. In this illustration, simulation is developed using above defined model for the operation of assumed Phase III multi-center clinical trial for 192 anemic patients in four districts like, District-1 (A1), District-2 (A2), District-3 (A3) and District-4 (A4) in two age groups like, 115 (R1), 15+ (R2) at three centers like, Center-1 (C1), Center-2 (C2) and Center-3 (C3) to compare and find the difference among four treatments like, Placebo A, treatment $\mathrm{B}$, treatment $\mathrm{C}$ and treatment $\mathrm{D}$. The depending study variable is the hemoglobin level of anemic patients.

The 192 anemic patients are arranged in the original order of the three factors such as, 2 age-groups, 3 centers and 4 districts in such a way that four treatments randomly allocated to twenty four cells which have 2 blocks based on gender and 4 anemic patients in each block. All the treatments are equally and randomly allocated in forty eight blocks. So each treatment can be replicated in forty eight blocks. It is assumed that there is no interaction between treatments, age-groups, centers, districts and blocks. A requirement of $\mathrm{UKCBD}$ is that the number of anemic patients (size 8) in each cell is equal but it is a multiple numbers of treatments (size 4). Each treatment combination contains in one block level of each factor.

Simulation is the replication of the process of existent in the real world. This simulated model is the imitation of the operation of phase III multi-center clinical trial study using four districts, age groups and centers as confounding factors for comparing four treatments in anemic patients. Inputs for placebo $\mathrm{A}$, treatment $\mathrm{B}$, treatment $\mathrm{C}$ and treatment $\mathrm{D}$ have been given scores from 1.3 to 1.6 (step 0.1 ) respectively. Input for sampling units are scores from 0.1 to 0.4 (step 0.1 ). These inputs are given to simulate the relevant range of hemoglobin values to imitate treatment $\mathrm{D}$ is better than treatment $\mathrm{C}$, treatment $\mathrm{C}$ is better than treatment $\mathrm{B}$, treatment $\mathrm{B}$ is better than placebo $\mathrm{A}$. In this simulated model, confounding factors are given scores from 1 to each of their natural order of levels, which can offer the alternative explanations for the experimental results. Randomization of UKCBD design minimizes or eliminates these three confounding factors. It allows making inference about the relationship between depending variable "hemoglobin level of anemic patients" and independent variable "treatments" as per simulation. Using ANOVA, it is going to be tested whether these treatments are differing 


\section{International Journal of Science and Research (IJSR) \\ ISSN (Online): 2319-7064}

Index Copernicus Value (2016): 79.57 | Impact Factor (2015): 6.391

significantly or not as per simulation for randomized data in UKCBD.

This design of experiment is discussed empirically with the depending study variable which is exhibiting linear trend through the simulated model. The values for depending study variable that appear in the final layout are the hemoglobin level of anemic patients (Table 1 to Table 4).

\section{Results}

In this demonstration, ANOVA is demonstrated with the independent variables/factors such as treatment, age-groups, centers, districts and blocks for a depending study variable like, the hemoglobin level of anemic patients. It examines effects of factors, simultaneously tests for differences among levels of the factors. It has been found that there is significant difference among treatments (Table 5).

The relative size of the two variations like (Treatments, Error), (Age-groups, Error), (Centers, Error), (Districts, Error) and (Blocks, Error) is used to indicate whether respective observed difference among the treatments, among the age-groups, among the centers, among the districts and among the blocks is real or due to chance. To find which treatments are different, post hoc test should be used to identify where the differences occur (Table 6).

Distribution of the data in the final design layout plan: The hemoglobin level of anemic patients

\begin{tabular}{|c|cc|cc|cc|}
\hline $\begin{array}{c}\text { Age- } \\
\text { groups } \\
\text { (Sex) }\end{array}$ & \multicolumn{5}{|c|}{ C1 } & \multicolumn{2}{|c|}{ C2 } & \multicolumn{2}{c|}{ C3 } \\
\cline { 2 - 7 } $1-15$ & $\mathrm{~A}$ & 5.3 & $\mathrm{C}$ & 7.6 & $\mathrm{C}$ & 9.1 \\
& $\mathrm{~B}$ & 5.8 & $\mathrm{D}$ & 8.2 & $\mathrm{~B}$ & 8.6 \\
Female & $\mathrm{C}$ & 6.3 & $\mathrm{~A}$ & 6.8 & $\mathrm{D}$ & 9.9 \\
& $\mathrm{D}$ & 6.8 & $\mathrm{~B}$ & 7.4 & $\mathrm{~A}$ & 8.2 \\
\cline { 2 - 7 } & $\mathrm{B}$ & 7.1 & $\mathrm{C}$ & 9.1 & $\mathrm{D}$ & 11.3 \\
& $\mathrm{C}$ & 7.7 & $\mathrm{~A}$ & 8 & $\mathrm{~A}$ & 9.3 \\
Male & $\mathrm{D}$ & 8.3 & $\mathrm{~B}$ & 8.7 & $\mathrm{~B}$ & 10.1 \\
& $\mathrm{~A}$ & 6.9 & $\mathrm{D}$ & 10 & $\mathrm{C}$ & 10.9 \\
\hline \multirow{3}{*}{$15+$} & $\mathrm{C}$ & 7.6 & $\mathrm{C}$ & 9.1 & $\mathrm{~A}$ & 9.2 \\
& $\mathrm{~B}$ & 7.2 & $\mathrm{~B}$ & 8.6 & $\mathrm{~B}$ & 10 \\
Female & $\mathrm{A}$ & 6.8 & $\mathrm{D}$ & 9.9 & $\mathrm{D}$ & 11.5 \\
& $\mathrm{D}$ & 8.4 & $\mathrm{~A}$ & 8.2 & $\mathrm{C}$ & 10.9 \\
\cline { 2 - 7 } & $\mathrm{C}$ & 9.1 & $\mathrm{~B}$ & 9.9 & $\mathrm{~A}$ & 10.5 \\
& $\mathrm{~A}$ & 8.0 & $\mathrm{~A}$ & 9.3 & $\mathrm{D}$ & 13 \\
Male & $\mathrm{D}$ & 9.9 & $\mathrm{D}$ & 11.5 & $\mathrm{C}$ & 12.3 \\
& $\mathrm{~B}$ & 8.8 & $\mathrm{C}$ & 10.9 & $\mathrm{~B}$ & 11.6 \\
\hline
\end{tabular}

\begin{tabular}{|l|rr|rr|rr|}
\hline \multirow{2}{*}{$\begin{array}{c}\text { Age- } \\
\text { groups } \\
\text { (Sex) }\end{array}$} & \multicolumn{4}{|c|}{ Table-2: District-2: Centers } \\
\cline { 2 - 7 } & \multicolumn{2}{|c|}{ C1 } & \multicolumn{2}{|c|}{ C2 } & \multicolumn{2}{|c|}{ C3 } \\
\hline $1-15$ & C & 7.6 & C & 9.1 & C & 10.6 \\
& B & 7.2 & D & 9.8 & B & 10.0 \\
Female & D & 8.3 & B & 8.7 & D & 11.5 \\
& A & 6.9 & A & 8.2 & A & 9.5 \\
& D & 9.7 & B & 9.9 & D & 12.9 \\
& A & 8.0 & D & 11.4 & B & 11.4 \\
Male & B & 8.7 & A & 9.4 & A & 10.7 \\
& C & 9.4 & C & 10.9 & C & 12.4 \\
\hline
\end{tabular}

\begin{tabular}{|l|rr|rr|rr|}
\hline $15+$ & $\mathrm{B}$ & 8.5 & $\mathrm{~B}$ & 9.9 & $\mathrm{~A}$ & 10.5 \\
Female & $\mathrm{C}$ & 9.2 & $\mathrm{D}$ & 11.4 & $\mathrm{D}$ & 13.0 \\
& $\mathrm{D}$ & 9.9 & $\mathrm{~A}$ & 9.4 & $\mathrm{~B}$ & 11.5 \\
& $\mathrm{~A}$ & 8.2 & $\mathrm{C}$ & 10.9 & $\mathrm{C}$ & 12.4 \\
\cline { 2 - 6 } Male & $\mathrm{B}$ & 9.9 & $\mathrm{~B}$ & 11.3 & $\mathrm{~B}$ & 12.7 \\
& $\mathrm{C}$ & 10.7 & $\mathrm{~A}$ & 10.6 & $\mathrm{C}$ & 13.7 \\
& $\mathrm{~A}$ & 9.4 & $\mathrm{C}$ & 12.3 & $\mathrm{D}$ & 14.7 \\
& $\mathrm{D}$ & 11.6 & $\mathrm{D}$ & 13.2 & $\mathrm{~A}$ & 12.1 \\
\hline
\end{tabular}

\begin{tabular}{|c|c|c|c|c|c|c|}
\hline \multirow{3}{*}{$\begin{array}{c}\begin{array}{c}\text { Age- } \\
\text { groups(Se } \\
\text { x) }\end{array} \\
1-15\end{array}$} & \multicolumn{6}{|c|}{ Table-3: District-3: Centers } \\
\hline & \multicolumn{2}{|c|}{$\mathrm{C} 1$} & \multicolumn{2}{|c|}{$\mathrm{C} 2$} & \multicolumn{2}{|c|}{$\mathrm{C} 3$} \\
\hline & B & 8.5 & $\mathrm{C}$ & 10.6 & D & 12.9 \\
\hline \multirow{3}{*}{ Female } & $\mathrm{C}$ & 9.2 & B & 10.0 & B & 11.4 \\
\hline & $\mathrm{D}$ & 9.9 & A & 9.4 & $\mathrm{C}$ & 12.3 \\
\hline & A & 8.2 & $\mathrm{D}$ & 11.6 & A & 10.8 \\
\hline \multirow{4}{*}{ Male } & B & 9.9 & $\mathrm{C}$ & 12.1 & $\mathrm{D}$ & 14.5 \\
\hline & $\mathrm{C}$ & 10.7 & A & 10.6 & $\mathrm{C}$ & 13.7 \\
\hline & A & 9.4 & $\mathrm{D}$ & 13.1 & A & 12.0 \\
\hline & $\mathrm{D}$ & 11.6 & B & 11.6 & B & 13.0 \\
\hline $15+$ & $\mathrm{C}$ & 10.6 & A & 10.5 & $\mathrm{C}$ & 13.6 \\
\hline \multirow{3}{*}{ Female } & B & 10.0 & B & 11.4 & A & 11.9 \\
\hline & $\mathrm{D}$ & 11.5 & $\mathrm{C}$ & 12.3 & $\mathrm{D}$ & 14.7 \\
\hline & A & 9.5 & D & 13.2 & B & 13.0 \\
\hline \multirow{4}{*}{ Male } & B & 11.3 & B & 12.7 & B & 14.1 \\
\hline & A & 10.6 & $\mathrm{C}$ & 13.7 & D & 16.2 \\
\hline & D & 13.1 & D & 14.7 & A & 13.3 \\
\hline & $\mathrm{C}$ & 12.4 & A & 12.1 & $\mathrm{C}$ & 15.4 \\
\hline
\end{tabular}

\begin{tabular}{|c|c|c|c|c|c|c|}
\hline \multirow{3}{*}{$\begin{array}{c}\text { Age- } \\
\text { groups(Se } \\
\text { x) }\end{array}$} & \multicolumn{6}{|c|}{ Table-4: District-4: Centers } \\
\hline & \multicolumn{2}{|c|}{$\mathrm{C} 1$} & \multicolumn{2}{|c|}{$\mathrm{C} 2$} & \multicolumn{2}{|c|}{ C3 } \\
\hline & $\mathrm{C}$ & 10.6 & C & 12.1 & A & 11.8 \\
\hline \multirow{3}{*}{ Female } & $\mathrm{D}$ & 11.4 & $\mathrm{~B}$ & 11.4 & $\mathrm{C}$ & 13.7 \\
\hline & B & 10.1 & $\mathrm{D}$ & 13.1 & $\mathrm{~B}$ & 12.9 \\
\hline & A & 9.5 & A & 10.8 & $\mathrm{D}$ & 14.8 \\
\hline \multirow{4}{*}{ Male } & B & 11.3 & D & 14.5 & $\mathrm{D}$ & 16.1 \\
\hline & D & 13.0 & B & 12.8 & $\mathrm{C}$ & 15.2 \\
\hline & A & 10.7 & A & 12.0 & B & 14.3 \\
\hline & $\mathrm{C}$ & 12.4 & $\mathrm{C}$ & 13.9 & A & 13.4 \\
\hline $15+$ & B & 11.3 & A & 11.8 & A & 13.1 \\
\hline \multirow{3}{*}{ Female } & $\mathrm{D}$ & 13.0 & $\mathrm{D}$ & 14.6 & $\mathrm{~B}$ & 14.2 \\
\hline & A & 10.7 & B & 12.9 & $\mathrm{C}$ & 15.3 \\
\hline & $\mathrm{C}$ & 12.4 & C & 13.9 & D & 16.4 \\
\hline \multirow{4}{*}{ Male } & B & 12.7 & B & 14.1 & A & 14.4 \\
\hline & A & 11.9 & C & 15.2 & C & 16.7 \\
\hline & C & 13.8 & D & 16.3 & D & 17.9 \\
\hline & $\mathrm{D}$ & 14.8 & A & 13.4 & $\mathrm{~B}$ & 15.8 \\
\hline
\end{tabular}




\section{International Journal of Science and Research (IJSR) \\ ISSN (Online): 2319-7064}

Index Copernicus Value (2016): 79.57 | Impact Factor (2015): 6.391

Table 5: Depending study variable: the hemoglobin level of anemic patients

UKCBD- ANOVA

\begin{tabular}{|c|c|c|c|c|c|}
\hline Source & $\begin{array}{c}\text { Type II Sum of } \\
\text { Squares }\end{array}$ & df & $\begin{array}{c}\text { Mean } \\
\text { Square }\end{array}$ & F & Sig. \\
\hline Model & $24874.282^{\mathrm{a}}$ & 11 & 2261.298 & 48504.246 & .000 \\
\hline Treatments & 135.722 & 3 & 45.241 & 970.398 & .000 \\
\hline Age-groups & 100.920 & 1 & 100.920 & 2164.707 & .000 \\
\hline Centers & 269.120 & 2 & 134.560 & 2886.276 & .000 \\
\hline Districts & 504.600 & 3 & 168.200 & 3607.845 & .000 \\
\hline $\begin{array}{c}\text { Blocks } \\
\text { (Sex) }\end{array}$ & 100.920 & 1 & 100.920 & 2164.707 & .000 \\
\hline Error & 8.438 & 181 & .047 & & \\
\hline Total & 24882.720 & 192 & & & \\
\hline \multicolumn{7}{|c|}{ a. R Squared =1.000 (Adjusted R Squared =1.000) } \\
\hline
\end{tabular}

Table 6: Depending study variable: the hemoglobin level of anemic patients

Post hoc test - Tukey HSD

\begin{tabular}{|c|c|c|c|c|c|c|}
\hline \multirow[t]{2}{*}{\begin{tabular}{|c|} 
(I) \\
Treatments
\end{tabular}} & \multirow{2}{*}{\begin{tabular}{|c|}
$(\mathrm{J})$ \\
Treatm \\
ents
\end{tabular}} & \multirow{2}{*}{$\begin{array}{c}\text { Mean } \\
\text { Difference } \\
\text { (I-J) }\end{array}$} & \multirow[b]{2}{*}{ Std. Error } & \multirow[b]{2}{*}{ Sig. } & \multicolumn{2}{|c|}{$\begin{array}{l}95 \% \text { Confidence } \\
\text { Interval }\end{array}$} \\
\hline & & & & & $\begin{array}{l}\text { Lower } \\
\text { Bound }\end{array}$ & $\begin{array}{l}\text { Upper } \\
\text { Bound }\end{array}$ \\
\hline \multirow[t]{3}{*}{ A } & $\mathrm{B}$ & $-.688^{*}$ & .0441 & .0 & -.802 & -.573 \\
\hline & $\mathrm{C}$ & $-1.467^{*}$ & .0441 & .0 & -1.581 & -1.352 \\
\hline & $\mathrm{D}$ & $-2.246^{*}$ & .0441 & .0 & -2.360 & -2.132 \\
\hline \multirow[t]{3}{*}{ B } & A & $.688^{*}$ & .0441 & .0 & .573 & .802 \\
\hline & $\mathrm{C}$ & $-.779^{*}$ & .0441 & .0 & -.893 & -.665 \\
\hline & $\mathrm{D}$ & $-1.558^{*}$ & .0441 & .0 & -1.673 & -1.444 \\
\hline \multirow[t]{3}{*}{$\mathrm{C}$} & $\mathrm{A}$ & $1.467^{*}$ & .0441 & .0 & 1.352 & 1.581 \\
\hline & B & $.779^{*}$ & .0441 & .0 & .665 & .893 \\
\hline & $\mathrm{D}$ & $-.779^{*}$ & .0441 & .0 & -.893 & -.665 \\
\hline \multirow[t]{3}{*}{$\mathrm{D}$} & A & $2.246^{*}$ & .0441 & .0 & 2.132 & 2.360 \\
\hline & $\mathrm{B}$ & $1.558^{*}$ & .0441 & .0 & 1.444 & 1.673 \\
\hline & $\mathrm{C}$ & $.779^{*}$ & .0441 & .0 & .665 & .893 \\
\hline
\end{tabular}

In this case, there appear to be significant differences in all the treatments, that is, Treatment-D, Treatment-C and Treatment-B are significantly different from Placebo-A. The post hoc tests imply that outcome of treatments on anemic patients to get cure is correctly found because the mean hemoglobin level of anemic patients significantly better than placebo for all the treatments as per simulation.

That is, treatment $\mathrm{D}$ is better than treatment $\mathrm{C}$, treatment $\mathrm{C}$ is better than treatment $\mathrm{B}$, treatment $\mathrm{B}$ is better than placebo A. Treatment-D is significantly different from other treatments with increased significant mean level of hemoglobin in anemic patients.

\section{Discussions}

ClinicalTrials.gov currently lists 236,008 studies with locations in all 50 States and in 195 countries. Multi -center clinical trials are trials conducted concurrently in several centers to assess the efficacy of the same treatments.

It is used to rectify the scarcity of the patients, complete the trial more quickly and represent a broader geographic spectrum. All new drugs and treatments pass the clinical trial process before being approved for use by the public. During clinical trials, researchers evaluate the safety and efficacy of these new drugs and treatments.
Large multi-center clinical trials, particularly Phase III trials, are conducted at several clinical research centers. Generally experimental designs are used in this clinical research. In this paper, experimental design UKCBD is demonstrated with the hypothetical data for the multi-center clinical trial approach. In case, the number of treatments is so large that a full replication in each block makes it too heterogeneous with respect to the characteristic under study, then smaller but homogeneous blocks can be used. In such a case the blocks do not contain full replicate of the treatments Experimental designs with blocks containing an incomplete replication of the treatments are called incomplete block designs [4].

In this block design, the researcher can divide experimental subjects into homogeneous blocks. Large number of treatments equal to the block size can be randomly assigned to the blocks. Then further randomization can be done with age-groups, centers and districts. This method is practically identical to the stratification. This block design reduces the variability within treatment conditions, which makes it easier to detect differences in the treatment outcomes.

In $\mathrm{UKCBD}$, the experimental units are grouped according to the various factors with different number of levels. This approach goes along with real life situations. In real life situations, it is not often to get an equal number of levels with associated independent variables. UKCBD is very much useful to handle such a type of independent variables which has an unequal number of levels.

UKCBD is demonstrated with the simulated model for the multi-center clinical trial approach. Between treatments, between rows, between columns, between altitudes and between blocks variations are eliminated from the within variation. Hence the majority of the effects are removed from the experimental error in this design compared to most of the other designs. So the error variance can be considerably reduced in UKCBD compared to CRD, RCBD, LSD and UKCD.

\section{Conclusions}

In real life situation, it is not always possible to form equal number of levels with all the associate factors. In order to proceeding along with real life situation, using this suggested new design, it is possible to accommodate either unequal or equal number of levels of the associated factors.

Researchers are interested in an area of methodological innovation. This design describes how to execute in an extensive and novel way towards generalization of the study with a deeper consideration of its real-life environment. It reveals in an efficient way, whether particular drug which has been invented is beneficial in the treatment of particular disease.

This design of experiment seems to be an efficient design for the larger sample size with more number of treatments to be compared in most type of the experimental works. Specifically, it is useful with complete three way layout for 


\section{International Journal of Science and Research (IJSR) \\ ISSN (Online): 2319-7064}

Index Copernicus Value (2016): 79.57 | Impact Factor (2015): 6.391

the larger number of treatments to be compared in the large multi-center clinical trials.

It includes larger number of participants, more number of treatments, different geographic locations, wider range of population groups and the ability to compare results among centers, all of which increase the generalizablity of the multi-center clinical trial study. This design will be useful for large multi-center clinical trials.

In many cases, efficacy will vary significantly between population groups with different backgrounds, like, genetic, environmental, ethnic, etc. This design can properly evaluate efficacy by adopting these groups in dispersed trial approach.

This design may be useful in thousands of clinical trials like, phase III, multicenter, randomized, double-blind, placebocontrolled study to evaluate the efficacy, safety, and tolerability of drug in the acute treatment of several diseases like, CVD, COPD, Hypertension, stroke etc.

In the analysis part, ANOVA is demonstrated with the independent variables such as treatment, age-groups, centers, districts and blocks for the randomized data of depending study variable in UKCBD. It reveals the efficiency of this design and its good randomization, to prove, in the above illustration; it reflects the results as per the data simulated through linear model. It also controls more variation and results in a smaller mean square error.

More investigation with real life studies to support this experimental design will build up the extent of this design.

\section{Acknowledgements}

Author is very much grateful to Dr. Manoj V. Murhekar, Director-in-charge, NIE, ICMR for his continuous encouragement in the development of this paper.

\section{References}

[1] Das MN, Giri NC. Design and Analysis of Experiments. New Age International (P) Ltd, New, $2^{\text {nd }}$ edition, Delhi, 2006.

[2] Leslie Kish. Statistical Design For Research. John Wiley \& Sons, 1987, P33-.

[3] Montgomery DC. Design and Analysis of Experiments. Wiley India $5^{\text {th }}$ Edition, 2006.

[4] Shalabh. MTH513 Analysis of variance, Teaching courses, lecture notes-4. Experimental designs and their analysis [online] available by Chapter4-anovaexperimental-design-analysis.pdf-. Adobe Acrobat Reader Dc, 2013.

[5] Vishwanth Reddy S. Anova \& experimental designs slide shares. Statistical analysis [online] available at http://www.slideshare.net/vishwanth555/anovaexperimental-designs, 2013.

[6] N. Uthayakumaran, "UK-Cubic Complete Randomized Design of Experiment: A Complete Three Way Layout for Large Multi-Center Clinical Trials", International Journal of Science and Research (IJSR), http://www.ijsrpublications.com/ijsr.net/archive/v6i12/v 6i12.php, Volume 6 Issue 12, December 2017, 104 110.

[7] Uthayakumaran N. Multi-label systematic sampling design: An unbiased estimator in the presence of linear trend. International journal of science and research, 2015, Vol. 4, Issue 8, 1343-1345.

[8] Uthayakumaran N. Multi-circular systematic sampling design. International journal of science and research, 2015, Vol. 4, Issue 9, 29-32.

[9] Uthayakumaran N. Weights proportional to size (WPS) Multi-systematic sampling design. International journal of science and research, 2015, Vol. 4, Issue 9, 834-837.

[10] Uthayakumaran N. Cuboidal systematic sampling method: An unbiased estimator in the presence of linear trend. International journal of statistics, 2015, Vol. 39, Issue 2, 1139-1145.

\section{Author Profile}

Dr. N. Uthayakumaran received his Ph.d. (Statistics) from Madras University, Chennai, Tamilnadu, India Presently he is a Principal Technical Officer at NIE, ICMR, Chennai and has published many research articles in Internationally Reputed Journals. 